\title{
Aggregate stability of some alluvial soils from Egypt
}

\author{
J. W. Kijne ${ }^{1}$ and B. G. Bishay² \\ 1 Department of Irrigation, Agricultural University, Wageningen, the Netherlands \\ 2 Land and Water Research Institute, Ministry of Agriculture, Guiza, Egypt
}

Accepted: 15 February 1974

\section{Summary}

The aggregate stability of silty clay loam and silty loam soil samples from the alluvial plain of the Nile valley and Delta was evaluated by means of the wet-sieving technique. Correlations of the aggregate index and the textural components of the samples and the composition of their cation exchange complex were established.

Especially the role of magnesium was studied in view of the hypothesis that the $\mathrm{Ca}-\mathrm{Mg}$ balance was the determining factor of the structural stability of these soils. Significant negative correlation was found for the silty clay loam samples between aggregate index and sodium content and the percentage of $0.05-0.10 \mathrm{~mm}$ particles, and positive correlation with percentage of clay particles. For the silty clay sample a positive correlation was found of the aggregate index and calcium content, and the $\mathrm{Ca} / \mathrm{Mg}$ ratio, and a negative one with $\mathrm{Mg}$ and $\mathrm{Na}$ percentage. So for the silty clay samples at least, the above mentioned hypothesis appears to be substantiated. In case of the silty clay loam samples there was evidence that the presence of exchangeable sodium aggravated the effect of magnesium on aggregate stability. In both groups of samples, however, percentage of $\mathrm{Na}$ was correlated at $\mathrm{P}<0.05$ with the $\mathrm{Ca} / \mathrm{Mg}$ ratio, which made it impossible to ascribe the harmful effect on aggregate stability to either an increase in sodium or a decrease in the $\mathrm{Ca} / \mathrm{Mg}$ ratio. Multiple regression involving the most significant constituent variables accounted for less than $40 \%$ of the total variance of aggregate stability. It is therefore concluded that the variables included in the multiple regression cannot be the exclusive cause of the aggregate stability, even though these variables among the many factors affecting the structure of the soil may well exert a strong influence.

\section{Introduction}

The close relations between aggregate stability and processes such as infiltration and erosion are obvious. However, the relations between aggregate stability and those factors which affect it are not so direct. Kemper \& Koch (1966) have listed a number of factors which influence aggregate stability, i.e. organic matter content, exchangeable cations, presence of amorphous sesquioxides and silicates, mycelia of organisms, microbial gums etc. Cultural practices, including irrigation and the quality of irrigation water, as well as weather conditions exert a definite influence on the relation between aggregate stability and the structure of the soil in the field.

Because so many factors influence soil structure, experiments attempting to correlate it with any of the factors known to affect aggregate stability have in some instances 
met with limited success. For example, the effects of exchangeable sodium and calcium on the physical properties of soils are fairly well established, but the role of exchangeable potassium and magnesium is more controversial. Even experiments which have shown significant correlations between aggregate stability and magnesium content have been criticized when the autors suggested that the presence of a high percentage of exchangeable magnesium was the causative factor of the poor structure of the soil (Koenigs \& Brinkman, 1964). The basis of doubt for such simple cause and effect relations is that there is a strong probability that aggregate stability is affected by several other factors at the same time. Thus Shauryguin (1935), Joffe \& Zimmerman (1945) van Schuylenborgh \& Veenenbos (1951) and Gill \& Sherman (1952) have concluded that exchangeable magnesium has an effect similar to that of exchangeable sodium. Others, such as Brooks et al. (1956) and El-Swaify et al. (1970), using several indices of structural stability, found no significant differences between the effects of magnesium and calcium.

The results of studies by van der Merwe \& Burger (1969) allow no such simple classification of $\mathrm{Mg}$ effects as identical to those of $\mathrm{Ca}$ or $\mathrm{Na}$. They found equally favourable effects of $\mathrm{Ca}$ and $\mathrm{Mg}$ saturation on permeability and modulus of rupture. However, when combinations of $\mathrm{Ca}-\mathrm{Na}$ and $\mathrm{Mg}-\mathrm{Na}$ were used, they found that the $\mathrm{Mg}-\mathrm{Na}$ soil was in much poorer structural condition than the $\mathrm{Ca}-\mathrm{Na}$ soil for identical ESP values. The balance between $\mathrm{Ca}$ and $\mathrm{Mg}$ may therefore be the determining factor. This view is upheld by Benecke (1963) who observed an increase is permeability of heavy marsh soils to be correlated with an increasing ratio of $\mathrm{Ca} / \mathrm{Mg}$ on the exchange complex. Bakker (1972) working with Australian soils obtained similar results. He found that the degree of dispersion of the soil remoulded at a given initial water content was much greater for the $\mathrm{Mg}$ soil than for the $\mathrm{Ca}$ soil. When small amounts of exchangeable $\mathrm{Na}$ were also present on the soil, the difference between $\mathrm{Mg}$ and $\mathrm{Ca}$ was accentuated.

The soils included in this study are alluvial soils of the Nile Valley and Delta in Egypt. It had been observed that they varied considerably in their physical characteristics, including soil structural stability, permeability and water holding capacity. It was therefore decided to evaluate the relation between the aggregate stability, as index of the structure of these soils, and their textural components and the composition of their cation exchange complexes, with a special interest in the role of exchangeable $\mathrm{Mg}$.

\section{Materials and methods}

The clay fraction of the alluvial soils of the Nile Valley and Delta consists mainly of montmorillonite, kaolinite and illite in varying proportions.

The present study was carried out in 26 locations distributed in three Governorates, namely: Beni-Suef, Kaliubia and Damietta at the Nile Valley of Egypt. From all the 26 profils studied, soil samples were taken from different layers. The following analyses were made on these samples:

1. Particle-size analysis. Percentages of colloidal clay, clay and silt were determined by the pipette method. Sodium hexametaphosphate was used as a dispersing agent. Sand fractions were separated by sieving to the fractions $2.00-1.00,1.00-0.50$, $0.50-0.25,0.25-0.10$, and $0.10-0.05 \mathrm{~mm}$, as described by Richards (19.54).

2. Aggregate size distribution (wet-sieving). The conventional Yoder method for aggregate analysis was followed. The screens used had the openings of $0.84,0.42,0.25$ 
and $0.10 \mathrm{~mm}$. The samples were air-dried and, when friable, passed gently through a 8 -mm screen to produce a more uniform sample. Duplicate subsamples were weighed, then moistened to saturation through capillarity and wet-sieved. After drying and weighing the soil on each sieve, the oven-dry soil taken from all the sieves was dispersed and washed through the sieves. The oven-dry weight of the primary particles remaining on each sieve was then determined. The results were expressed in the following ways: aggregates $2.00-0.84 \mathrm{~mm}, 0.84-0.42 \mathrm{~mm}, 0.42-0.25 \mathrm{~mm}, 0.25-0.10 \mathrm{~mm}$ and the aggregation index.

3. The cation exchange capacity was estimated by the method of Richards (1954). The soil was completely saturated with sodium bij means of normal sodium acetate solution. Then the sample was washed with $95 \%$ ethanol. The adsorped sodium was replaced by extraction with a normal solution of ammonium acetate and then the sodium concentration of the combined extract after dilution was determined by the flame photometer.

4. Exchangeable sodium and potassium percentage were determined by the flame photometer as described by Richards (1954).

5. Exchangeable calcium and magnesium percentages were determined in sodium chloride extract by the versinate method as described by Abd El Barr (1948).

\section{Results and discussion}

The aggregate stability by means of the wet-sieving technique (either by the Yoder technique or by a modification as suggested by Bryant et al., 1948) has been determined by many workers on vastly different soils. It remains, however, a rather arbitrary method as there is no certainty that the disruptive action of wet-sieving simulates the processes occurring in the field during rainfall or irrigation and subsequent drying. The wet-sieving treatment consists of wetting to produce incipient failure of the aggregates, followed by mechanical shaking and abrasion to separate the particles along their failure planes. The greatest problem in wet-sieving is the treatment of the samples before analysis. Air drying decreases the percentage of large aggregates in favour of smaller ones, and this effect is greater the more intense the drying process is. The breaking up of the larger aggregates is greater the more rapidly the samples are wetted on the sieves of the wet-sieving apparatus. Immersing the soil in water causes more destruction of the larger aggregates because of air explosion than wetting by capillarity. The soils of this study are usually irrigated by flooding and the period between irrigations is long enough to cause severe drying of the surface soil. Wetting in the field may be even more destructive under these circumstances than the gentle wetting under capillarity of the wet-sieving method.

In a comparison of four methods for determining the stability of aggregates it was found by Williams et al. (1966) that in wet-sieving the use of air-dry aggregates gave the best differentiation between aggregates from different rotation treatments. Differentiation between samples was aimed at in this study, not to acquire absolute values of aggregate stability, because these do not exist. For this reason and for the convenience of the method which requires only a limited amount of work per sample and can be set up as a standard laboratory practice, the wet-sieving technique was adopted in this study, without further testing the influence of varying the conditions of the technique.

Of the samples 34 belonged to the textural class of silty clay loam and 32 to silty clay. 


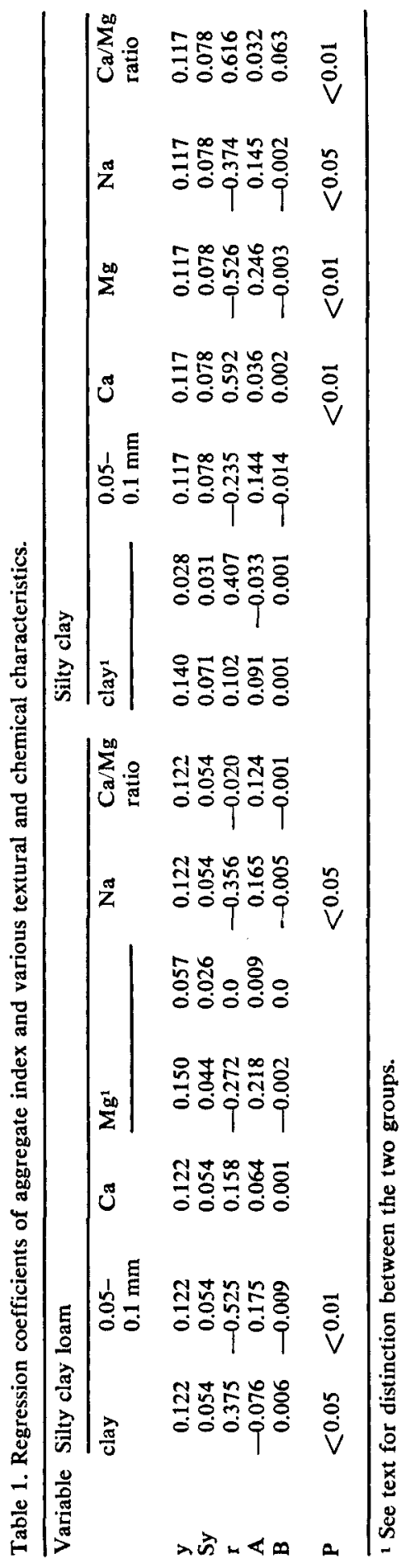


The numbers of silt loam and clay samples were too small to justify statistical analysis.

Linear regression coefficients were calculated for the relation between aggregate index and the percentage of clay particles and particles with a diameter of $0.05-0.10$ $\mathrm{mm}$, and the percentage of exchangeable $\mathrm{Ca}, \mathrm{Mg}$, and $\mathrm{Na}$, as well as with the fraction $\mathrm{Ca} / \mathrm{Mg}$. Correlations with other size fractions, with $\mathrm{CaCo}_{3}$ content and percentage of exchangeable $\mathrm{K}$ were found to be insignificant. The calculated correlation coefficients (r) are listed in Table 1, together with the mean aggregate index (y), the standard error of estimate (Sy), and the coefficients $\mathrm{A}$ and $\mathrm{B}$ of the regression $\mathrm{y}=\mathrm{A}+\mathrm{Bx}$. The significance of the regression is also indicated in Table 1; correlation coefficients were not always significant for both groups of samples.

For the silty clay loam samples the aggregate stability was best correlated with the percentage of particles between 0.05 and $0.10 \mathrm{~mm}$, and for the samples of silty clay with the ration $\mathrm{Ca} / \mathrm{Mg}$. These correlations are plotted in Fig. 1 and 2, respectively. A negative effect of coarser particles on aggregate stability has been observed before. For example, Messemaeckers \& Arnold (1972), using a finer division of textural

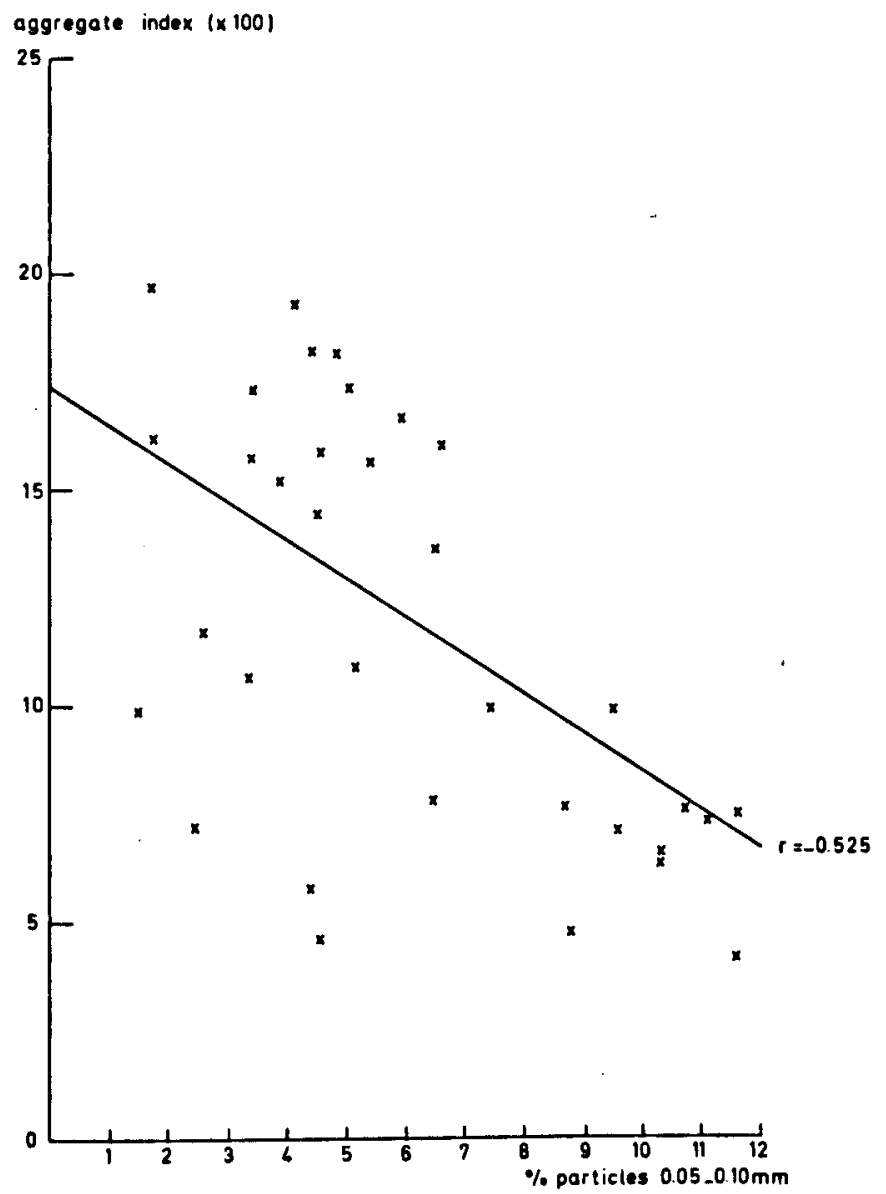

Fig. 1. Correlation of aggregate index and percentage of particles of $0.05-0.10 \mathrm{~mm}$ for silty clay loam.

Neth. J. agric. Sci. 22 (1974) 


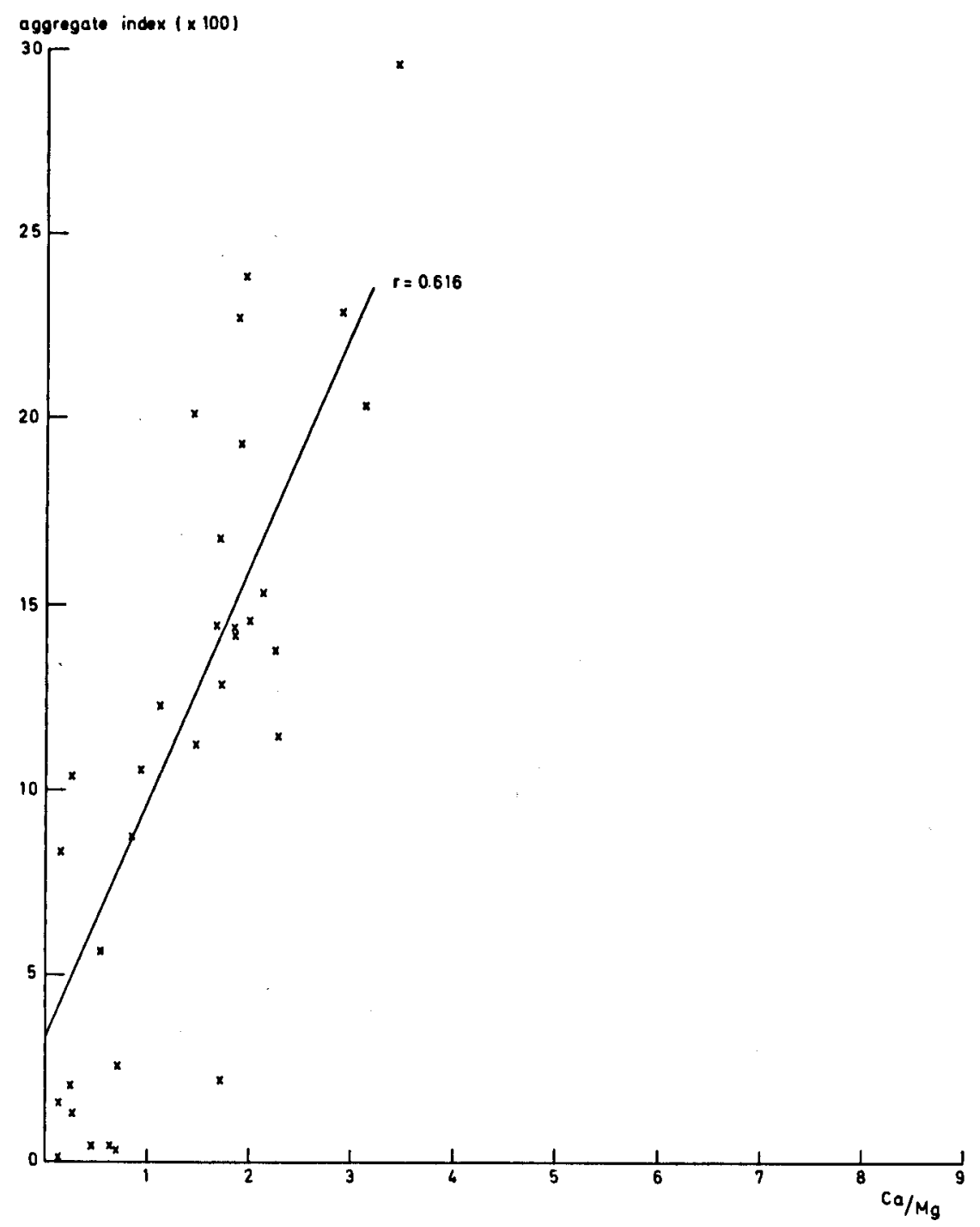

Fig. 2. Correlation of aggregate index and $\mathrm{Ca} / \mathrm{Mg}$ ratio for silty clay.

separates in the silt-sized particles, found that the percentage of $0.016-0.032 \mathrm{~mm}$ particles was the most important negatively correlated with ped size and hence with aggregate stability.

The aggregate index of the silty clay loam samples was not correlated significantly with the percentage of exchangeable $\mathrm{Mg}$ (see Table 1). Graphical representation of this function, however, indicated the possibility of two groups of data (Fig. 3). Statistical analysis of the data showed indeed that the two groups were significantly different in their exchangeable $\mathrm{Na}$ content (' $\mathrm{t}$ ' test of significance between two sample means, $0.05<\mathrm{P}<0.10)$ and in their content of particles with size $0.05-0.10 \mathrm{~mm}(\mathrm{P}<0.01)$. 


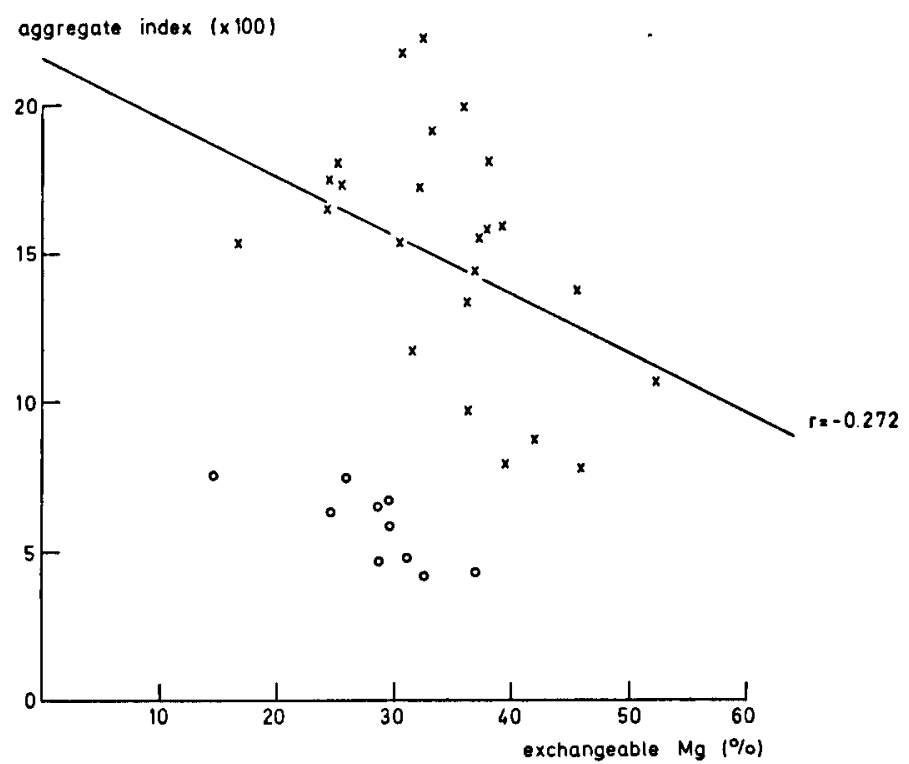

Fig. 3. Correlation of aggregate index and percentage of exchangeable $\mathrm{Mg}$ for silty clay loam.

The correlation of the group with the higher mean aggregate index $(0.150)$ just failed to be significant with respect to $\mathrm{Mg}$ percentage, at the $\mathrm{P}<0.05$, and the other group $(\bar{y}=0.057)$ showed no correlation between aggregate index and $\mathrm{Mg}$ percentage. This latter group had a higher $\mathrm{Na}$ content (mean value of $10.65 \%$ versus $8.22 \%$ )and higher content of particles of $0.05-0.10 \mathrm{~mm}(8.55 \%$ versus $4.80 \%)$. This result appears to be in agreement with the studies by van der Merwe \& Burger (1969), and Bakker (1972), mentioned in the introduction, in which it was reported that the presence of exchangeable $\mathrm{Na}$ tended to aggrevate the effect of $\mathrm{Mg}$ on the aggregate stability. Nevertheless, the harmful effect on aggregate stability cannot be ascribed with certainty to either the increase in $\mathrm{Na}$ content or in $\mathrm{Mg}$ content. For the silty clay loam group as a whole the percentage of $\mathrm{Na}$ is correlated with the $\mathrm{Ca} / \mathrm{Mg}$ ratio (i.e. $\mathrm{Ca} / \mathrm{Mg}=$ $2.74-0.084 \mathrm{Na} ; \mathrm{r}=-0.355 ; \mathrm{P}<0.05)$, but for the group with the mean aggregate index equal to 0.150 , identified above, this correlation between $\mathrm{Na}$ and $\mathrm{Ca} / \mathrm{Mg}$ is not significant. The effect of $\mathrm{Na}$ by itself was significant at $\mathrm{P}<0.05$ for both the silty clay loam and the silty clay samples (see Table 1).

A distinction between two groups could also be made in case of silty clay for the relation between the aggregate index and clay content. This correlation itself was not significant, the sample with the small mean aggregate index being too small to make the correlation coefficient of 0.407 significant at $\mathrm{P}<0.05$. The two groups of samples however, differed significantly in terms of percentage of exchangeable $\mathrm{Na}$ and $\mathrm{Ca}$ $(P<0.01)$. The relation between aggregate index and the other independent variables could not be improved by separating the sample into these two groups or in any other way.

It may appear surprising that in one group of samples the relation between aggregate index and exchangeable Ca content is highly significant (silty clay), and with the other group of samples only very weak (silty clay loam). Baver (1935) reported that statistical 
analysis of 77 different soils in the USA showed no significant correlation between amount of exchangeable calcium and granulation. There is a similar difference in significance of the correlation between the ratio of $\mathrm{Ca} / \mathrm{Mg}$ and aggregation, implying that the hypothesis expressed in the introduction that the balance between $\mathrm{Ca}$ and $\mathrm{Mg}$ could be the determining factor in aggregate stability is not always confirmed. This is not just a matter of a different range of values of the $\mathrm{Ca} / \mathrm{Mg}$ ratio in the two groups of samples: the mean ratio was 2.005 (standard error 0.9 ) in case of the silty clay loam and 1.358 (standard error 0.749 ) in the silty clay samples. Moreover, for both groups of samples the $\mathrm{Ca} / \mathrm{Mg}$ ratio is correlated at $\mathrm{P}<0.05$ with the percentage of exchangeable Na. This was pointed out above already for the silty clay loam group. Because of this correlation between $\mathrm{Na}$ and $\mathrm{Ca} / \mathrm{Mg}$ the matter is rather confounded. Others who have worked on the $\mathrm{Mg}$ problem have not attempted to establish whether this correlation existed. In some instances it was possible to study the relation from the data published in the literature; for the two regions from where the samples analysed by Schuylenborgh \& Veenenbos (1951) were taken, for example, the correlation between $\mathrm{Na}$ and $\mathrm{Ca} / \mathrm{Mg}$ was between $\mathrm{P}<0.05$ and $\mathrm{P}<0.10$. Van der Merwe \& Burger (1969) reported the cation composition for one profile at 7 depths. For these samples also the correlations between $\mathrm{Na}$ and $\mathrm{Ca} / \mathrm{Mg}$ was between $\mathrm{P}<0.05$ and $\mathrm{P}<0.10$. In many other instances it is not possible to study this relation from literature sources because $\mathrm{Ca}$ and $\mathrm{Mg}$ are lumped together for the calculation of the sodium adsorption ratio. A significant correlation between $\mathrm{Na}$ and $\mathrm{Ca} / \mathrm{Mg}$ is to be expected where the soils in a region were derived from the same parent material or have been in contact for a long time with irrigation water of constant cation composition.

A large number of multiple regressions were calculated. The most meaningful involved only the amount of exchangeable sodium and the content of $0.05-0.10 \mathrm{~mm}$ particles for the silty clay. The other variables added little to the significance of the relation obtained, either because they showed only a weak correlation with the aggregate index, or were mutually correlated with one of the two variables included. These relations are: tor silty clay loam:

$$
\mathrm{AI}=19.8-0.964 \mathrm{Na}-0.208 \text { (part.) }
$$

where $\mathrm{AI}=100$ aggregate index

$\mathrm{Na}=$ percentage of exchangeable sodium

part. = percentage of particles of $0.05-0.10 \mathrm{~mm}$

for silty clay:

$\mathrm{AI}=6.31-0.0786 \mathrm{Na}+5.46(\mathrm{Ca} / \mathrm{Mg})$

where $\mathrm{Ca} / \mathrm{Mg}=$ the ratio of the amounts of exchangeable $\mathrm{Ca}$ and $\mathrm{Mg}$.

The analysis of variance for Eq. 1 indicated that $F=6.81(P<0.01)$ and $R=$ 0.554 , so that the fraction of the variance attributable to regression is 0.306 .

For Eq. 2 , we have $F=10.1(P<0.01)$ and $R=0.606$, so that the fraction of the variance attributable to regression is 0.369 .

It should be noted that in Eq. 2 the two variables are correlated. The next best multiple regression equation for silty clay was:

$$
\mathrm{AI}=102.09-2.19 \text { (part. })+6.546(\mathrm{Ca} / \mathrm{Mg})
$$

with $\mathrm{F}=7.18(\mathrm{P}<0.01)$ and $\mathrm{R}=0.575$.

In terms of prediction, therefore, these equations have a low order of precision.

Kemper \& Koch (1966) in their study of aggregate stability of over 500 samples from western parts of the USA and Canada found also a multiple correlation which could account for only $31 \%$ of the total variance of aggregate stability. Variables included in the analysis of Kemper \& Koch (1966) were also organic matter content 
and $\mathrm{Fe}_{2} \mathrm{O}_{3}$ content. The omission of organic matter as a variable could indeed be a weak point of the present study. These soils are only known to have a low organic matter content but its variability is not known.

Other possible sources of variance in aggregate stability could be associated with differences in intensity of cultivation and perhaps differences in clay mineralogy of the samples.

A greater differentiation between size fractions in the present study probably would have increased the portion of aggregate stability variance that could have been accounted for in a multip!e regression.

The correlations obtained, therefore, do not indicate that the two variables included in Eq. 1, 2 and 3 are the exclusive cause of aggregate stability, but is can fairly be assumed that of the many factors affecting the structure of the soil, these exert a strong influence.

\section{References}

Abd El Bar, 1948. Laboratory treatment with gypsum of black alkali samples from Wadi Tumilat (Egypt). M. Sc. Thesis, Faculty of Agriculture, Caïro University, Egypt.

Bakker, A. C., 1972. The comparative effects of exchangeable $\mathrm{Ca}, \mathrm{Mg}$ and $\mathrm{Na}$ on the stability in water of aggregates from the subsoils of red brown earths. M. Sc. thesis. University of Adelaide, Department of Agricultural Biochemistry and Soil Science.

Baver, L. D., 1935. Factors contributing to the genesis of soil microstructure. Bull, Am. Soil Survey Assoc. 16: 55-56, as quoted in: L. D. Baver, W. H. Gardner \& W. R. Gardner, Soil physics, 4th ed. John Wiley, New York, 1972, p. 143.

Benecke, P., 1963. Graduations of structure and its relation to permeability. Mitt. dt. Bodenk. Ges. 1: 253-266.

Brooks, R. H., C. A. Bower \& R. C. Reeve, 1956. The effect of various excangeable cations upon the physical conditions of soils. Proc. Soil Sci. Soc. Am. 20: 325-327.

Bryant, J. C., T. W. Bendixen \& C. S. Slater, 1948. Measurement of the water-stability of soils. Soil Sci. 65: $341-345$.

El Swaify, S. A., S. Amed \& L. D. Sindale, 1970. Effects of adsorbed cations on physical properties of tropical red and tropical black earths. J. Soil Sci. 21: 187-198.

Gill, R. \& G. Sherman, 1952. Properties of the gray hydromorphic soils of the Hawaiian Islands. Pac. Sci. 6: 137.

Joffe, I. S. \& M. Zimmerman, 1944. Sodium, calcium, and magnesium ratios in the exchange complex. Proc. Soil Sci. Soc, Am. 9: 51-55.

Kemper, W. D. \& J. E. Koch, 1966. Aggregate stability of soils from Western United States and Canada. U.S. Dep. Agric. tech. Bull. 1355.

Koenigs, F. F. R., \& R. Brinkman, 1964. Influence of partial sodium and magnesium saturation on the structural stability of clay soil. Proc. 8th int. Congr. Soil Sci. 2: 219-226.

Merwe, A. J. van der \& R. du T. Burger, 1969. The influence of exchangeable cations on certain physical properties of a saline-alkali soil. Agrochemophysico 1: 63-66.

Messemaeckers van de Graaff, R. H. \& R. W. Arnold, 1972. Blocky ped size in relation to the soil composition, depth and drainage. Mimeographed report, International Institute of Land Reclamation and Improvement, Wageningen.

Richards, L. A. (Ed.), 1954. Diagnosis and improvement of saline and alkali soils. U.S. Salinity Lab., U.S. Dep. Agric., Handb. 60.

Schuylenborgh, J. van \& J. S. Veenenbos, 1951. Over de invloed van magnesium op de structuur van sedimenten. Landbouwk. Tijdschr. 63: 709-714.

Shauryguin, P. J., 1935. Influence of adsorbed magnesium upon the physical properties of the soil. (Russian.) Pochvouedenic 2: 167-173.

Williams, B. G., D. J. Greenland, G. R. Lindstrom \& J. P. Quirk, 1966. Techniques for the determination of the stability of soil aggregates. Soil Sci. 101: 157-163. 